\title{
KERUKUNAN BERAGAMA (STUDI TENTANG PERAN "HUHU KEBIE" SEBAGAI SARANA INTEGRASI DI PULAU SABU NTT)
}

\author{
H. ABDUL AZIS AL BONE
}

\section{Pendahuluan}

Bumi Indonesia terkcnal scbagai ternpat pertemuan agama-agama besar dan sccara resmi diakui keberadaannya di Indonesia, sepcrti Islam, Kristen, Protestan, Katholik, Hindu dan Budha. Disamping agama- agama resmi, di Pulau Sabu yang menjadi sasaran penelitian ini tcrdapat agama lokal yang disebut "Jingitin" (Halaik).

Kehadiran agama-agama besar, tidak hanya mempengaruhi kedudukan agama asl i, te-tapi juga mcnimbulkan kctegangankctegangandidalammasyarakat. Bagi ketiga agama, yaitu Islam, Hindu dan Budha, tidak hanya bergcrak dibidang spiritual, teapi dalam bidang politik (kenegaraan). Bagi mcrcka sccara prinsip, agama identik dengan ncgara. Hal demikian tcrwujud dalam scjarah Nusanlaradengan berdirinya kcrajaan Hindu, Budha dan Islam. Dalam Ncgara RI mcrdeka, agama sebagai sumber kctcgangan dan pcrselisihan agak dapat d i rcdakan dengan di terim anya Pancasi 1 a dan UUD 1945, dimana prinsip kebesaran bcragama ditetapkan menjadi hukum ncgara. Namun demikian, hal itu tidak berarti kcricuhan tidak terjadi sama sekali. Walaupun umat agama-agamabesar hidup bcrdampingan dalam masyarakat yang sama, harus diakui bahwa jarak jiwa sosial dari golongan yang satu dengan yang lain, sc- bclum tahun 1965-an cukupjauh. Agamaagama itu saling mcnulup diri, masingmasing hidup dalam dunianya sendiri. Komunikasi terbatas pada hubungan urusan hidup sehari-hari tidak pemah ada pcrgaulan antarapemcluk-pcmulukitu sebagai umat bcragama ang baik. Keadaan sepcrti itu penyebab dari keresahan-keresahan tcrscbut di atas (Hendropuspito, 1984 : 188 - 189).

Sumber kercsahan lain ilaha masalah penyebaran agama. Khusus untuk pemcluk agama yang mcrasa tcrpanggil untuk berdakwah sepcrti umat Kristen dan umat Islam. Namun masalah yang paling ruwet ialah munculnya larangan penyebaran agama kepada golongan yang sudah bcragama (Henropuspito, 1984 : 190).

Fokus bcragama di pulau kecil NTT yaitu Pulau Sabu yang dikcnal rukun, dimana hubungan darah dikalangan umatumat bcragama sclalu tcrpelihara dan dijunjung tinggi, sckaligus mengetahui faktor-faktor yang mencntukan dalam pembinaan kcrukunan bcragama. Sasaran penelitian ini adalah di Kccamatan Sabu Barat yang cukup majemuk.

\section{Gambaran Umuni}

Di Pulau Sabu tcrdapat dua kccamatan, yaiiu Kccamatan Sabu Timur dan Kccamatan Sabu Barat. Namun yang menjadi 
sasaran penclitian ini adalah di Kecamatan Sabu Barat, karena tcrdapat umat yang majemuk.

Luas Kecamatan Sabu Barat seluruhnya $290.52 \mathrm{~km}^{2}$, dengan perincian, dataran pulau Sabu bahagian barat, $252,92 \mathrm{~km}^{2}$, dataran pulau Raivua, $36,97 \mathrm{~km}^{2}$, dataran pulau Dana, $0,63 \mathrm{~km}^{2}$. Hampir sebagian wilayah terdiri dari padang rumput, selain pohon lontar dan pohon kclapa. Iklimnya topis serta tanahnya kcring tcrutama di pesisir pantai.

Pcnduduk Sabu Barat (1987) bcrjumlah 40.211 orang, mayoritas beragama Kristen Prolcstan.

Kecamatan Sabu Barat ini terdiri dari 25 desa, dan yang menjadi sasaran penclitian ini adalah Desa Mubba (Seba) ibukota Kecamatan Sabu Barat, dimana hanya di Desa tersebut terdapat tiga agama besar yaitu : Islam, Kristen Protestan dan Katholik, disamping agama lokal va ilu Halaik.

Seba (Mcbba) sebagai ibukota kecamatan termasuk desa yang teramai di pulau Sabu karena pasar dan pertokoan hanya terdapat di desa ini. Dcrmaga pelabuhan yang besar dan disandari kapal-kapal besar dari dan ke Sabu tcrdapat di desa Seba. Lalu lintas dari pulau Flores dan Sumba yang menuju Kupangharusmampirdi pelabuhan Seba.

Dengan adanya listrik masuk desa $\mathrm{m}$ aka Seba yang sclama ini agak gelap di malam hari menjadi terang benderang. Disamping itu dengan masuknya listrik, wawasan m asyarakat Seba bcrtambah luas lewat televisi, dan khusus bagi pedagang menambah penghasilan dengan usaha membuat es lilin.
Desa Seba terdiri dari 5 dusun dan 20 rukun tentangga (RT). Luas desa 05,24 km $\mathrm{km}^{2}$ dengan jumlah penduduk 2.827 orang, dan termasuk desa yang terdapat di pulau Sabu, rata-rata $540 / \mathrm{km}$. Adapun data penduduk menurut agama untuk tahun 1987, adalah : Kristen Protestan 2.396 jiwa, Islam 188 jiwa, Katolik 165 jiwa, Jugitiu 78 jiwa. Mala pencaharian penduduk mayoritas petani, 478 orang, pegawai negeri/swasta 62 orang, pedagang 21 orang dan ABRI10 orang.

Scsuai dengan kondisi tanah yang kcring dengan iklim tropisnya, kehidupan penduduk hanya mcnyandarkan kepada air nira pohon lontar yang mcreka sadap setiap pagi dan petang. Air nira discbut "due", itulah yang mereka gunakan sebagai sarapan pagi dan lauknya ikan tawar/asin.

Mcreka yang lebih banyak menggantungkan hidupnya kepada due ini, antara lain dari kampung Waihibo, Leomondanu, Lobohiha, Raiwatta. Namun badan mcreka kckar dan kuat, hal ini titunjukkan dengan kemampuan mcreka mcmikul satu kuinta! bcras dengan jarak yang cukup jauh, yaitu dari dcrmaga ke toko sekitar 100 meter. Mcreka umumnya bckcrja sebagai buruh pelabuhan disaat ada kapal.

Adapun pola makan mereka adalah pagi hari cukup due (air nira) dan ikan bakar, makan siang dengan nasi beras/ jagung dan kalau taka da nasi cukup makan gula air dari nira dicampur kclapa tua atau kacang hijau. Dan malam hari kcmbali due atau gula air.

Mcreka yang tinggal $2-3 \mathrm{~km}$ dari pantai, mcreka hidup bcrladang seperti dimusim hujan menanam padi ladang (tcrae) 
dan jagung scrta kacang tanah. Dimusim kcmarau mercka mcnanam bawang, sawi, tomat, cabe, dan dengan dibangunnya cekdam oleh pcmcrintah, maka sawah dapat digunakan untuk mcnanam padi. Namun mcnurut mercka bahwa hasil panennya cukup untuk kepentingan sendiri. Dari pengamatan penulis, tcrnyata kchidupan pctani ladang dan sawah lebih baik dari pctani pohon Ionian

Mercka yang hidup scbagai pclani lontar tcrnyaia juga gigih mencari uang, baik scbagai buruh pclabuhan maupun scbagai nclayan tradisional dengan menggunakan jala alau mancing. Disamping itu scbagaimana umumnya masyarakat Scba yang baragama Kristcn mercka bclcrnak babi dan dengan menjual babi itulah mercka bcrhasil mcnyckolahkan anak mcreka kepcrguruan tinggi. Karcna tekad mercka adalah "biarlah mercka susah dan mclarat asal anaknya nanti senang". Banyak anak-anak Sabu yang menduduki posisi penting di Kupang, scperti camat, bupali, dosen, gum dan lain-lain.

Mcnurut tokohmasyarakat, Abd. Kadir dan Moses Wco bahwa kemcnangan Golkar adalah disamping kcberhasilan pembangunan yang sangat dirasakan sampai kc pedesaan, juga sistcm pembinaan kader dimana remaja diikutsertakan dalam wadah Karang Taruna dan AMPI. Namun pada tahun 1960-an di zaman orde lama, pengikut PKI yang minoritas dengan segala macam kelicikan bcrusaha mcmpengaruhi masyarakat untuk menerima idcologi Komunisnya yang kadang-kadanf dengan mengadakan teror dan mengadu domba. Pada tahun 1963 tcrjadi pembakaran rumah dan toko-toko yang dimiliki umat Islam. Tidak puas dengan itu, mcreka membunuh 100 ekor kuda yang diberangkatkan ke SUmbawa dengan cara menebarkan DDT pada rumput. Pada tahun 1962, sebelum -kcjadian di atas, mercka menghasud penduduk asli mengcroyok keluarga besar Haji yusuf, tctapi tidak smcpat memakan korban. Bcrhasilnya menumpas G30S/PKI merupakan wujud kcberhasilan orde baru yang sangat mengesankan mercka.

Scjak orde baru, kchidupan kegotongroyongan tcrlihat dengan jelas. Mcreka mcmbangun mmah dengan swadaya, mulai dari mencbang pohon lontar, mendirikan liang-tiang, dan khusus wanita menganyam atap dari daun lontar. Stclah dislcl scbagai satukcrangka rumah khusus dikerjakan oleh kerabat dekat, maka untuk mendirikan rumah. diundang scsama warga secara bergotong royong dan ahli rumah hanya mcnyiapkan pcrbckalan makan siang.

\section{Kehidupan Beragama}

Penduduk di Kecamatan Sabu Barat berpenduduk mayoritas beragama Kristen Protestan yang taat, dimana gercja mencapai 44 buah terisi penuh. Adapun masjid hanya satu buah dengan kapasitas 300 orang jamaah. Gereja Katolik hanya 1 buah dengan konisi cukup sedcrhana.

Kegiatan sekolah minggu pada jam 07.00 cukup ramai dipadati anak-anak remaja dan oranglua. Selain kegiatan kebaktian di gercja, maka mengadakan kebaktian dari rumah ke rumah yang dipimpin oleh penatua, pendeta atau majlis gercja. Kegiatan tcrscbut disamakan Kasasi (Kahahi). Sctiap hari besar Kristen mercka 
mengadakan kebaktian di gereja, seperti hari Natal, Paskah, dan lain-lain. Bahkan ada yang mengadakan natal di rumah mereka dengan mendatangkan pendeta. Dan pada hri natal dan tahun baru itulah mereka mengadakan kunjungan dari rumah ke rumah. Dan suatu ciri khas, bahwa bila mereka bertcmu tidak sekedar salam-salaman, tetap saling bcrciuman, baik sesama laki-laki, atau antara laki-laki dan perempuan. Keluarga muslim juga berkunjung kcpada keluarga Kristen untuk menyampaikan ucapan selamat. Umat Katholik, walaupun minorias dan lcbih banyak pendatang dari Flores yang bertugas sebagai pcgawai, guru dan ABRI, tetapi mereka taat bcragama, khusus setiap minggu mengadakan misa di gereja dan juga mengadakan peringatan Hari Besar Kristen.

Penganut Jingitin (Halaik) mcrupakan kcpcrcayaan animisme yang masih hidup tetapi bcrangsur hilang digeser olch agama besar yang sudah mcndominasi di dacrah tcrsebut, terutama tcrbawa oleh keluarga yang menganut agama Kristen Protestan. Mereka melaksanakan acara pcribadatan hanya pada waktu tertcntu, seperti pertukangan musim, waktu panen sebagai tanda syukur mereka mengadakan sabung ayam dan pedoa (mcnari bcrsama membuat lingkaran sambil bcrpcgangan pinggang antara pria dan wanita). Namun pcdoa mcrupakan sarana pembinaan kcrukunan bcragama dimana mclalui suasana tcrsebut scmua umat bcragama tcrlibat dan berintegrasi. Mereka mcnari dengan gembira dan dari sana banyak dari remaja yang mcncmukan jodoh.
Dari hubungan darah akibat perkawinan terkaitlah mereka dan keturunannya dalam struktur keturunan disebut silsilah keluarga (hubungan kekerabatan yang paten) lebih dikenal dengan istilah "Huhu Kebic". Huhu Kebie sangat dipeliharanya dan dijunjung tinggi. Apabila terjadi konflik makapara orang tua mengatakan "kalian masih bcrsaudara" (a'a ari) dan mereka saling bcrangkulan.

Mengenai umat Islam di Sabu, walaupun minoritasternyata taat beragam a. Hal ini dilihat terutama pada hari Jumat dimana mereka berbondong-bondong ke masjid. Dan kegiatan pengajian di masjid cukup scmarak baik pengajian kaum ibu dan anak-anak scrta remaja. Mereka mendapat bantuan tenaga pengajian khusus guru ngaji dari psantren JawaTimuryangdibiayai olch Rabitha ALam Islamiyah. Umumnya mereka tcrmasuk orang yang mampu karena pedagang, disamping itu ada pula diantara mereka yang bcrkcrja sebagai guru SD, SMP dan SMA.

Pada hari-hari besar Islam mereka mengadakan kegiatan perlombaan mulai dari musabaqah Al-Qur'an, pidato dakwah, puitisasi sampai pcrtndinganolahraga. Pada kegiatan olahraga seperti bola kaki, volly, pimpong danc atur, ini turut mclibalkan umat Kristen dengan klub olahraga mereka.

Pada hari raya Idul Fitri, mereka saling kunjung mengunjungi, dimana leman scjawat yang bcragama Kristen Protestan atau Katholik atau Halaik, apalagi yang berhubungan darah, ikut menyampaikan ucapan selamat dan ikut mengecapi kuekuc lebarari. 
Sebagai umat yang mayoritas mereka terdorong untuk meningkatkan aktifitas keagamaannya, sehingga setiap hari besar Islam ikut diketahui dan dinikmati keberadaannya oleh umat lain. Pada hari kematian khusus nujuh hari, kerabat kerja yang beragama Kristen ikut menyumbang beras, ayam atau kambing, sebagai tanda simpatik mereka.

\section{Kerukunan Beragama}

Interaksi antara umat beragama tentu harus dilihat dari dua sisi yaitu integrasi dan konflik. Konflik antara umat beragama jarang terjadi tetapi konflik intern umat beragama khusus Kristen Protestan karena perbedaan sekte dan aliran, pada umumnya tahun 1970-an sering terjadi.

Integrasi antar umat beragama berlangsung dalam berbagai aktifitas dalam kehidupan sehari-hari, utama yangberkaitan dengan profesi yang digeluti antara lain :

\section{Melalui hubungan usaha}

Anwar sebagai pedagang dan pengusaha yang giat di bidang pemborong bangunan dapat membina hubungan baik dengan pengusaha/pedagang yang berbeda agama yaitu David. Hal ini terlihat dari adanya kesediaan Anwar memberikan pinjaman uang kepada David (non muslim) sebanyak puluhan juta rupiah tanpa bunga. Hal itu sejak orang tua merka sudah bersahabat dan bertetangga.

\section{Hubungan buruh majlkan}

Ahmad sebagai seorang pedagang dan pemborong beragama Islam, mempekerjakan beberapa buruh yang bcragama non Muslim. Bahkan kepala tukangnya bcr- agama Kristen Protestan. Dan kebanyakan dari buruh-buruhnya, termasuk tidak punya hubungan darah atau kerabat dengannya. Namun hubungannya dengan para buruh sangat akrab.

Ahmad sangat mempercayai tukangtukangnya, sehingga hanya sekali-sekali baru mengontrol pckerjaan mereka. Justru karena kcpercayaan itulah mereka bckerja dengan penuh tanggungjawab. Yang sering diingatkan hanya bahwa kalau kerja kita baik, kita akan dipercayakan oleh pemerintah dan rezeki anda lebih panjang. Bila tidak ada borongan, mereka sering datang ke toko Ahmad membawa ayam, sayur, dan lain-lain, sedang dari keluarga Ahmad juga memberi oleh-oleh untuk keluarga mereka seperti beras atau baju bekas, dan lain-lain.

Dcmikian pula bila da acara selamatan di lingkungan keluarga Ahmad, mereka datang membantu untuk memasang tenda, membuat janur, mengatur kursi bahkan ada yang membawa ayam untuk pesta. Sebaliknya bila ada keluarga mereka yang kawin atau meninggal dunia, keluarga Ahmad memberikan bantuan uang dan bagi yang meninggal dunia ditambah kain hitam untuk kebutuhan penguburan. Bila mereka ke toko AHmad, mereka ikut membantu mengatur barang di toko, mengangkat karung beras, melayani pembeli scakan tokonya sendiri. Dan pada hari raya Idul Fitri mereka datang bersilaturrahmi, demikian juga sebaliknya.

\section{Hubungan profesi}

Karena ada dari keluarga Muslim yang bckerja sebagai guru SD, SMP maka teman seprofesi ini langsung menjadi teman akrab 
dan mereka saling tolong menolong dalam banyak hal, baik dari segi materi maupun inmateri, Dari segi materi misalnya saling meminjam uang atau beras, dan lain-lain. Dari segi inmateri seperti apabila terjadi masalah pribadi langsung dimintapendapat atau nasehat temannya walaupun berbeda agama. Hubungan profesi telah membuat ikatan rasa secorps dalam tugas.

Seorang guru SD bernama Sari pah yang bcrteman dengan Loni teman gurunya yang berbeda agama. Begitu dekatnya sehingga walaupun Saripah telah menikah, Loni scwaktu-waktu nginap di rumah Saripah, kadang-kadang sampai berhari-hari, sepcrti saudara sckandung saja.

\section{Hubungan kekerabatan (Huhu Kabie)}

Bagi masyarakat Sabu hubungan kekerabatan sangal dijunjung tinggi. $\mathrm{Hu}-$ bungan kekerabatan antara agama asalnya karcna ikatan tali perkawinan. Banyak dari kcluarga Muslim yang menikah dengan gadis Sabu yang bcragama Kristen atau Halaik, kemudian mengikuti agama suaminya yaitu Islam. Dari sinilah mulai ada hubungan darah antar agama. Hubungan kekerabatan di Sabu demikian tcrpclihara, baik, sehingga dijalin dalam suatu silsilah yang sering dinyanyikan olch orang tua-tua adat. Kemudian kita dapat mongetahui dari mana hubungan kita dengan scscorang mcnurut silsilah tcrsebut. Inilah yang disebut "Huhu Kebie".

Huhu Kcbie ini dijunjung tinggi dimana dengan pertalian darah ini hubungan kekerabatan terpelihara baik. Hubungan kekerabatan lebih diutamakan dari hubungan agama karena menreka menganggap bahwa agama adalah hubungan pribadi dengan Tuhan.

Pada suatu ketika terjadi pertengkaran antara seorang remaja Islam dengan seorang remaja Kristen, sehingga saling mongepal tinju hanya masalah pribadi dan sepele. Tiba-tiba seorang remaja Kristen lain yang punya hubungan darah dengan remaja Islam ikut membantu remaja Islam dengan mcmbanting remaja Kristen tadi dari belakang dengan mengatakan "ncdi' aei ia" (ini saudaraku). Sctclah didamaikan, dibacakan "Huhu Kebie" (silsilah kcturunan/ kekerabaan) ternyata scmua masih ada pertalian darah dari datuk dan ncnek. Dikatakanlah kepada mereka bahwa "Mu ta a'a aki" (kalian masih bersaudara).

Dalam kasus lain yang terjadi pada kcluarga H. Kasim dimana rumahnya terbakarkarena ulah PKI pada tahun 1960-an. Ternyata dalam tempo 3 bulan, seluruh kerabat dari istrinya yang scmuanya beragama Kristen, dengan rasa tanggung jawab mulaid ari mencbang pohon lontar, membuat kcrangka rumah, dinding dan atap, mereka secara bersama-sama membangun rumah baru H. Kasim. Menurut H. Kasim, modal yang disiapkan hanya makanan unluk mereka yang bekcrja scharian tanpa upah.

Dari kenyataan ini tcrgambar bahwa hubungan kekerabatan yang dihimpun dalam Huhu Kebie mcrupakan sarana intcgrasi yang ampuh dalam pembinaan kcrukunan bcragama di Seba.

Kasus lain mcnurut Abd. Kadir, pada waktu orang luanya dalam kondisi sangat sulil sctclah rumah tcrbakarhabisdan paccklik dimana padi, beras dan jagung mcmang 
tidak beredar di toko-toko. Pada suatu pagi pendeta Lobo kebetulan lewat di depan rum ah sebagaimana kebiasaan beliau tiap pagi jalan pagi dan mampir ke rumah orang tua Abd. Kadirdanngobrol dengan akrabnya karena kebetulan mempunyai hu! keluarga dengan ibunya Abd. Kadir yag asli Sabu. Ibu Abd. Kadir menyampaikan kepada pendeta Lobo bahwa mereka kchabisan makanan. Pendeta Lobo marah dan mengatakan kenapa kamu diam-diam saja, sayakan saudaramu. Pendeta Lobo sebagai tokoh agam a Kristen Protestan yang discgani langsung pulang dan tiba-tiba bcbcrapa saat kemudian sudah datang utusan dari pendeta membawa beras $10 \mathrm{~kg}$,jagung $5 \mathrm{~kg}$ tanpa mau menerima uang ketika dibayarkan oleh orang tua Abd. Kadir yang beragama Islam.

Adapun konflik antara agama, jarang tcrjadi karena peranan para tokoh-tokoh agama besar, cukup bcrfungsi demikian juga pemerintah.

Pcrnah terjadi seorang gadis Kristen Protestan mempunyai hubungan baik dengan jaka Muslim. Karena sudah hubungan dekat, maka orang tua jaka Muslim melamar dan ditolak oleh orang tua gadis. Gadis tadi bcrtekad untuk kawin dengan pemuda idamannya dan lari ke rumah keluarga pemuda Muslim. Terjadi konflik antar keluarga kedua bclah pihak, namun dapat diselcsaikan oleh tokoh agama kedua bclah pihak dimana Pendeta FX Huma sebagai pendeta senior yang discgani memberi nasehat kepada keluarga gadis agar kita serahkan kepada kedua remaja, sebab mereka yang akan menjalani kehidupan rumah tangga. Terjadilah pcrnikahan dimana sang gadis mengikuti agama suami.

Yang sering terjadi adalah knflik intern Kristen Protestan. Seperti sebuahkasus dimana seorang anggota Majlis Gereja GMIT Lobodei, seteliih mendengar ceramah atau diskusi dengan seorang advent lentang larangan memakan daging babi, kemudian cukp dipahaminya secara baik, diapun mcmberanikan diri mengembangkan dalam pertcmuan anggota Majlis Gereja, maksudnya untuk mendapatkan tanggapan yang bisa dilerima secara rasio. Setelah mendengarpendapat dari para Majlis Gereja yang tak logis menurutnya, maka pcrdebatan itu disampaikan kepada tokoh GMIT pendcla FX Huma. Pendeta menjawab secara diplomasi dan netral, bahwa hal itu tergantungimam kita. Maka anggota Majlis Gereja tadi dan para pengikut dan anggota jemaainya mmisahkan diri dari Gcrejf Lobodei dan menjadi pengikut advent. Demikian juga yang terjadi di Kampung Mcnia, yang menjadi pusat advent Sabu bertcntangan dengan GMIT. DI Teriwu pusat Pantekosta bertcntangan dengan GMIT. Di Lobohika basis Bethel bertentangan dengan GMIT. Hal ini dapat dimaklumi bahwa konflik ini terjadi karena GMIT mayoritas selalu merasa terancam, sedang yang minoritas lebih agresif dengan missinya.

Untuk mengatasi konflik antar dan intern urn at beragama, Pemerintah Kecamatan Sabu Barat mengadakan Badan Kontak Agama pada tahun 1983 dengan tugas mcnyelcsaikan masalah yang berkaitan dan 
mcnjurus kepada SARA dalam rangka memantapkan kerukunan beragama, dengan susunan pengurus tcrdiri dari:

Kctua : Pendeta FX Huma (Kristen Protestan)

Sckrctaris : Ninggeding (Sekrctaris Camat).

Anggota : 1. Abd. Kadir (Islam)

2. Ninggeding (Bethel).

3. Wadu (Pantekosta)

4. Nguru (Advent).

\section{Penutup}

1. Kchidupan beragama di Kecamatan Sabu Barat khususnya di Dcsa Scba (Mcbba) cukup semarak.

2. Inlegrasi antara urn at beragama ber-

\section{KEPUSTAKA A N}

Hcndropuspito, Sosiologi Agama, Kanisius, Malang 1984

Nico L Kana, Dunia Orang Sawu, Pcnerbit Sinar Harapan, 1981 Jakarta.

Kadir, M. Abd. Al-Qalam, No. 7 \& 8 Th. Ill (Juli - Descmbcr) 1992 Ujungpandang. langsung dalam berbagai aktifitas seperti hubungan dagang atau usaha, hubungan profesi, hubungan buruh majikan dan hubungan kekerbatan.

3. "Huhu Kcbie" menjadi sarana ampuh tcrwujudnya kerukunan beragama di Pulau Sabu, Nusa Tenggara Timur.

4. Kerukunan beragama dapat terpelihara karena pcranan lembaga adat sepcrti pedoa dan huhu kcbie serta peran dari lembaga Badan Kontak Agama.

5. Konflik intern umat Kristen yang terjadi adalah karena simbol agama yang mcrupakan atribut identitas masing-masing penganut agama ikut diaktifkan dalam mclakukan interaksi sosial antar mercka dalam kchidupan masyarakat.

Kocntjaraningrat, Manusia Kebudayaan di Indonesia, 1985 Pcnerbit Djambatan, Jakarta.

Thomas, F.O'dca, Sosiologi Agama, Rajawali, Jakarta. 1985 